Revista Iberoamericana, Vol. LXXI, Núm. 210, Enero-Marzo 2005, 263-273

\section{EN DICIEMBRE LLEGABAN LAS BRISAS DE MARVEL MORENO: CUERPO A CUERPO, LA DESVALORIZACIÓN DE LA SEXUALIDAD FEMENINA}

\author{
POR \\ FLORENCE BAILLON \\ Universidad Andina Simón Bolívar, Ecuador
}

La lucidez es en el fondo una herida

René Char

Marvel Moreno hubiera podido hacer suyo este verso del poeta francés, puesto que su mirada sobre el género humano fue a la vez penetrante, sin ilusión y llena de compasión. Nacida en 1939, originaria de la clase privilegiada de la costa colombiana, Marvel Moreno hizo de la Barranquilla de su juventud la escena principal de su obra ${ }^{1} \mathrm{y}$, sobre todo, de su única novela publicada hasta ahora, En diciembre llegaban las brisas. Cabe decir que Marvel Moreno salió de su ciudad natal en 1969 y nunca retornó, ${ }^{2}$ primero por motivos personales y luego por razones de salud. ${ }^{3}$ Esta aclaración biográfica tiene un doble sentido más allá de su interés anecdótico: en relación con lo literario, la Barranquilla de la novela no existe más. La ciudad se volvió una creación del exilio y, por ende, Marvel Moreno pudo mirar su lugar de origen desde lejos, mezclando su experiencia caribeña con la intelectualidad parisiense. Por otro lado, como veremos en este artículo, la única opción que se propone a los personajes femeninos -en todo caso- para lograr la independencia verdadera y el reconocimiento de su yo, es huir de esa sociedad que, según Julio Olaciregui, la escritora nos describe como:

[...] un mundo de arribistas, de patológicos caracteres envueltos en la locura de una sociedad que se fundó, como se han fundado muchos pueblos del mundo, sobre la esclavitud, la guerra, el contrabando, hasta llegar a cierto entendimiento social. (Olaciregui 95-96)

\footnotetext{
${ }^{1}$ Barranquilla es el escenario de Algo tan feo en la vida de una señora bien y de En diciembre llegaban las brisas.

${ }^{2}$ Como dice la narradora de la novela, Lina, "Los años han pasado y no he vuelto a Barranquilla (...)” (En diciembre, 281) y "Los años han pasado. No he vuelto ni creo que vuelva nunca a Barranquilla" (283).

${ }^{3}$ En 1972, se declaró un lupus por lo cual los médicos franceses le pronosticaron un máximo de dos años de vida; finalmente, sobrevivió veintitrés años a su enfermedad.
} 
La imagen de ese mundo sin amor no fue fácil escribir y tampoco de leer. La salud delicada de la autora le hizo temer el dejar su obra incompleta, lo que explica su estructura tripartita y la autonomía de sus partes que cuentan, cada una, la historia de un personaje femenino principal -Dora, Catalina, Beatriz- en un presente narrativo, contado por la voz de Lina Insignares, sin ningún diálogo. Cada una de las partes se abre con un retrato de mujer miembro de la familia de Lina (la abuela, la tía Eloísa, la tía Irene). La presencia de las dos generaciones anteriores es válida para todos los personajes de la novela, permitiendo al lector medir la evolución social y familiar. Estos personajes aparecen en las tres partes pero se modifica su importancia en el texto en función de la relación que mantienen con la protagonista. ${ }^{4}$ Es así como a lo largo de la historia, el punto de vista se desplaza de un personaje a otro, de una situación a otra y de un tiempo a otro, ilustrando a Pound, "Savoir ce qui précède et ce qui suit vous aidera à mieux comprendre ce qui se passe". ${ }^{5}$

Para lograr el análisis global de la sociedad barranquillera, la escritora recurre a todas sus lecturas de autodidacta: historia, sociología, antropología, sicoanálisi, la Biblia y a esa tensión entre los discursos se suma la tensión, perfectamente dominada, entre un vocabulario preciso, casi clínico y una frase laberíntica que cuenta un hecho narrado por otro, conciente o no, distante o no, legítimo o no, creíble o no. La descripción de esa sociedad patriarcal caribeña de la década del cincuenta, se enfoca en la temática de la sexualidad femenina como el espacio en donde mejor se expresa el poder, por ser el más perturbador. Marvel Moreno demuestra y desmonta los mecanismos que hicieron de un impulso biológico ${ }^{6}$ un discurso estructurado política y socialmente, con la conjugación de las acciones de los hombres, el apoyo de la Iglesia y la complicidad de las madres.

La escritora denuncia la manera cómo la violencia y la represión agreden a las mujeres por el simple hecho de serlo. Es útil precisar que En diciembre llegaban las brisas trata solamente de las clases alta y media del grupo dominante que regula las relaciones humanas y distribuye los roles sociales, apoyándose sobre los valores morales cristianos divulgados por la Iglesia, la misma que asume el papel de agente de control. Además de ser la clase social de origen de la autora, su presencia exclusiva se debe también al hecho de que solamente ahí la sexualidad tiene un precio: allí los hombres buscan cómo vivir de las mujeres.

Marvel Moreno, desde su exilio parisino, nos ofrece la imagen de una Barranquilla desoladora y asfixiante, donde el ambiente apestoso de la sociedad en vía de putrefacción vence sobre el calor propio del clima de la costa colombiana. ¿Qué es lo que hace que este

\footnotetext{
${ }^{4}$ En una carta, Plinio Apuleyo hace comentarios a Jacques Gilard sobre la elaboración de la novela: "La Marvel se ha sentado en su sillón, con un cuadernito sobre las rodillas, y se ha puesto a escribir su novela sobre Barranquilla. ¿Con qué va a salir? Me temo que con algo parecido a la Biblia. Me habla de seiscientas páginas, de tres generaciones y otras visiones del mismo género apocalíptico.” (Gilard)

${ }^{5}$ Ezra Pound, Les Cantos, Canto LXXVII. “Saber lo que precede y lo que sigue les ayudará a entender mejor lo que pasa”. (La traducción es mía)

${ }^{6}$ Vemos en la novela la importancia que Marvel Moreno atribuye a los impulsos, “Al principio no había sido el verbo, decía su abuela, porque antes del verbo había habido la acción y antes de la acción el deseo. En su origen cualquier deseo era y sería siempre puro, anterior a la palabra, ajeno a toda consideración de orden moral” (En diciembre, 37).
} 
cuadro tropical, con sus playas -lugar de encuentro de los amantes-, su vegetación exuberante, su clima, su vida fácil para la clase alta -casas inmensas, domesticidad numerosa, Country Club,...-, se transforme en un universo hollywoodiense, en una realidad aterradora, poblada de mujeres neuróticas, dependientes, de hombres violentos, ambiciosos, donde los antiguos habitantes son tan enfermizos como los emigrantes? Se trata de una Barranquilla que quisiera ser cosmopolita, sin lograr superar ni su provincialismo ni su racismo. Marvel Moreno pinta con precisión el momento crucial en el cual se encuentra Barranquilla en las décadas del cincuenta y del sesenta: víctima del boom económico, crispada sobre antiguos valores que no se apoyan más sobre la realidad y con aires de una modernidad que no logran cambiar su estructura profunda.

El punto que cristaliza entonces la resistencia más profunda al cambio de esta sociedad en transición es la sexualidad femenina. Los hombres atados a su sed de poder y convencidos de la legitimidad de la ley del más fuerte, necesitan regular la sexualidad de las mujeres para que ésta no se vuelva un elemento explosivo. Mejor dicho, el control de la sexualidad femenina es absolutamente indispensable puesto que es la condición sine qua non que permite a la élite -entendida como élite económica- mantenerse en su lugar privilegiado. La manipulación debe ser completa y es por eso que se impone en las "hembras". Los machos barranquilleros dirigen la sexualidad de sus madres para que no arriesguen por motivos sentimentales la herencia familiar, ${ }^{8}$ la de sus esposas por razones evidentes, la de sus hijas, que vírgenes hasta el matrimonio aseguran al casarse la pureza de la sangre y/o el nivel económico de la familia; ${ }^{9}$ la de sus nietas que se vuelven una tentación, ${ }^{10}$ la de sus empleadas para gozar de ellas, la de las prostitutas para que no abusen de su sabiduría y hasta la de sus gatas:

\footnotetext{
${ }^{7} \mathrm{Al}$ inicio, la novela se intitulaba Muy cerca del mar, que son las últimas palabras del libro "No he vuelto ni creo que vuelva nunca a Barranquilla. A mi alrededor nadie conoce siquiera su nombre. Cuando me preguntan como es, me limito a decir que está junto a un río, muy cerca del mar" (En diciembre 283).

${ }^{8}$ Los hermanos de Beatriz descubren que su padre tiene una amante y le hacen un chantaje para apoderarse de la fortuna familiar: "los cinco hermanos Avendaño no iban a perder la oportunidad de desenmascarar al fin los turbios manejos financieros de su padre obligando a la Nena a admitir de una vez por todas el fracaso de su matrimonio y, en consecuencia, a recuperar el legítimo control de su fortuna" (En diciembre188).

${ }^{9}$ Por ejemplo, la conveniencia que tiene para todos el probable matrimonio entre Beatriz y Jean-Luc Freisen, un desequilibrado mental: "En realidad, Jean-Luc no quería nada, salvo disipar las dudas sobre su equilibrio mental pasando ante su familia como el supuesto novio de una linda heredera cuya alcurnia y distinción no tenía necesidad de demostrarse. Gustavo Freisen no cabía en sí de contento: las predicciones del Manco estaban a punto de realizarse y sus concesiones a aquella ciudad que aborrecía, pero de la cual dependía su bienestar, iban a dar al fin los mejores frutos: uno de sus hijos, el menos agraciado, como si fuera poco, lograría alianzar su posición social entrando en el clan de los Avendaño. [...] La propia Odile Kerouan se mostraba inclinada a ponerles una sordina a sus resentimientos conyugales aliándose a su marido en la empresa de seducir a aquella muchacha de buena familia que, además, presentaba la ventaja de ser blanca ciento por ciento y hablar un francés irreprochable” (En diciembre 245).

${ }^{10}$ ver el caso “ejemplar”de María Fernanda Valenzuela, “podía al fin nombrarla infamia: haber sido violada brutalmente a los diez años por su propio abuelo, constituía un traumatismo difícil de superar: más difícil aún si al ser descubierta por su padre, bañada en sangre, éste había decidido
} 
Le parecía verlos aún junto a Gustavo Freisen, los ojos iluminados por un brillo malévolo, enfrentándose a la pobre gata que enloquecida de dolor intentaba proteger su cría; ni siquiera habían tratado de matarla a ella primero para evitarle el sufrimiento de ver torturar a sus hijos uno tras otro hasta la muerte [...] mientras los hermanos Freisen golpeaban cada gatico de tal modo que su agonía durara el mayor tiempo posible, Gustavo Freisen se encargaba de rechazar a punta de palazos las embestidas de la madre. (224)

Frente a esta situación, las mujeres desarrollan una sexualidad alterada como resultado de la mezcla de sus propios deseos, de los prejuicios ligados al catolicismo, del modelo de sus madres y de la presión de sus maridos. Justamente, parece oportuno detenerse un momento en la relación antinatural y por lo tanto legítima en ese cuadro, entre madres y yernos: la alianza es necesaria para la perennidad del sistema:

Por haber sufrido del poder femenino tanto como del masculino, y sabiendo que el primero puede ser tan cruel y abusivo como el otro, [Marvel Moreno] no caía en el maniqueísmo de los años 70, que les echaba en cara a los hombres todos los pecados mientras les reconocía a las mujeres todas las virtudes. (Fourrier 28)

La pasividad de las esposas es secundada por las madres:

Al principio intentó con horror sofocar, contener o destruir aquella cosa inaudita que Dora rezumaba por cada poro de su piel; al no lograrlo, pues a pesar de fajas y vendajes los senos de su hija se erguían y sus caderas se redondeaban y la caballera que crecía a borbotones rompía las cintas de trenzas y colas de caballo, trató fascinada de hacerla suya: como una enredadera se le trepo al cuerpo y quiso respirar con sus pulmones, mirar a través de sus ojos, latir al ritmo de su corazón: escudriñó su cerebro con la misma enervada obstinación con la que registraba las gavetas de su tocador y leía las páginas de sus libros y cuadernos: la obligó a pensar en voz alta, a contarle sus secretos, a revelarle sus deseos: terminó por poseerla antes que ningún hombre, abriéndole a todo hombre el camino de su posesión. (16)

encerrarla en un cuarto aislándola del resto de la familia a fin de ocultar la verdad y borrar el oprobio recibido, atacando, no al culpable, respetable patriarca, propietario de la mejor hacienda del departamento, sino a la víctima, la niña que por haber encarnado la tentación, debía ocultarse en una habitación casi a oscuras, a quien nadie podía acercarse así llorara de día y de noche, y que sobreviviría gracias a la cesta de comida izada hasta su ventana al anochecer" (En diciembre 16364). Una vez casadas, las mujeres se descargaban de las faenas domésticas sobre sus criadas y entraban en la feliz ociosidad de tardes pasadas en el "Country” jugando cartas hasta el anochecer, mientras cedían a los antojos de su apetito encargando sándwiches, tazas de té y algunos tragos disimulados en "Coca-Colas". Esa ordenada monotonía parecía sentarles perfectamente bien; repetían una y otra vez los gestos de la tarde anterior, de miles de tardes idénticas, hasta que sus mentes adormecían y sus cuerpos funcionaban como entidades ávidas de jamón y queso caliente entre dos rebanadas de pan, engordándose poco a poco, y también poco a poco aumentando la cantidad de ginebra que los sirvientes del "Country" mezclaban a las "Coca-Colas"con exquisita discreción” (En diciembre 232). 
Cuando no es así, como en el caso de Catalina, la hija procura encontrar en su interior un medio para no someterse al modelo impuesto. En primer lugar, las madres no tienen ningún poder, pues el único imperio sobre el cual reinan es el cuerpo y la mente de sus hijas ya que los hijos logran escapar. ${ }^{11}$ El dominio debe ser eficiente para que las hijas contraigan matrimonio con el hombre adecuado: hay que ver el destino de la herencia o, al contrario, la manera de salvarla, así como evitar el mestizaje social y/o racial, excepto cuando se torna -lastimosamente- inevitable. Una vez casadas, la experiencia materna apaga cualquier veleidad de independencia; las mujeres no pueden gozar fuera del matrimonio, y muchas veces ni siquiera dentro, hasta la sexualidad autorizada por la Iglesia es manipulada por los maridos. El miedo del hombre frente al goce femenino es revelador de un malestar social intenso. Los cuerpos son campos de batalla en donde se lucha por controlar la existencia del otro con el fin de anularlo y domesticar sus impulsos. ${ }^{12}$

Los personajes de Marvel Moreno, tanto hombres como mujeres, llevan todos vidas confusas, llenas de una violencia que bordea el desastre. Son personajes preocupados, angustiados, asediados sin tregua por los otros y, sobre todo, por la mirada ajena: ellos se ven a través de los demás. El narrador está fuera de la historia, ${ }^{13}$ los discursos son transcritos, contados, actualizando así la polifonía de las voces. ${ }^{14}$ La narración es precisamente aquello que concretiza lo mirado, es en particular la conciencia femenina que se sabe vigilada por la mirada de otro que se proyecta inquisidora para descalificar. ${ }^{15} \mathrm{La}$ mirada es uno de los recursos más importantes mediante el cual se expresa el "voyeurismo" o la curiosidad malsana masculina, y a su vez el aliado para afirmar el poder.

Marvel Moreno trabaja la oralidad a través del chisme, defecto social típicamente latinoamericano, sin que sintamos o suframos la ausencia de diálogo, el chisme es lo que se dice del otro cuando no está presente. En esta sociedad tan conformista, de códigos indiscutibles, el personaje se somete a la imagen que los otros se hacen de él. Marvel Moreno combina pensamiento, intenciones, percepción de la realidad de cada personaje

\footnotetext{
11 "Pero el gran error de Odile Kerouan fue el de creerlo ligado a ella eternamente, como si un hombre joven y en perfecta salud aceptara mucho tiempo quedarse en ese estado de simbiosis uterina, negándose otros amores y contentándose con la triste rutina de los burdeles.”, op. cit. 235 ${ }^{12}$ Marvel Moreno tampoco parece estar conforme con el "hembrismo"final: "Ellas ignoraban la sumisión [...] hacían el amor con desenvoltura para tormento de sus amantes que se sentían como cerezas tomadas con distracción de un plato. Quizá sólo yo comprendía que ese frenético consumo de hombres elegidos y devorados sin ternura ni compasión, era simplemente la venganza que una generación de mujeres ejercía, sin saberlo, en nombre de muchas otras” (En diciembre 282-83).

${ }^{13} \mathrm{El}$ narrador-testigo conoce a las protagonistas y a veces interviene, pero su propia historia no aparece. En cuanto a confundir Lina y Marvel, el único punto común seguro es su lugar fuera de la historia. Marvel Moreno declaró: "sea cual sea su sexo, el escritor es marginal, está "fuera" de la cultura dominante para observarla, analizarla, criticarla o condenarla” (Damjanova, "La voz femenina de Marvel Moreno...”, 107).

${ }^{14}$ No hay un yo porque no hay un narrador en primera persona ni un auténtico protagonista.

${ }^{15}$ La temática de la mirada está presente en toda la obra de Marvel Moreno. Ver Algo tan feo en la vida de una señora bien, donde Laura pierde toda su autoestima bajo la mirada culpabilizadora de su marido. Pensar también la construcción del cuento "La noche maravillosa de Madame Yvonne", en el cual todos los eventos son vistos a través de las miradas de Madame Yvonne y del Capitán Rouleau.
} 
con las otras subjetividades y con el punto de vista objetivo del narrador. La escritora utiliza visiones de varias disciplinas para ofrecer una imagen lo más completa posible. Al ser los personajes vistos desde el exterior -nunca escuchamos su voz interior-, podemos percibir la arbitrariedad de lo que le sucede. Por ejemplo, el lector sabe el efecto que provoca el cuerpo de Dora sobre los demás, pero no lo que siente Dora al provocarlos:

\begin{abstract}
Dora encontraba natural saberse deseada y se habría quedado boquiabierta si alguien se hubiese tomado el trabajo de explicarle que era sobre todo con el fin de verla que los muchachos del "Biffi" se encaramaban sobre el muro del colegio corriendo el riesgo de dejar las manos en aquella barrera de vidrios. Para Dora eso, como los vagabundos que abrían su bragueta apenas la veían sola en el jardín de su casa, estaba en el orden natural de las cosas, más aún, debía de corresponder al pie de la letra a lo que su madre le decía sobre la naturaleza masculina por esencia corrompida y encaminada a sumir a las mujeres en la abyección. (14)
\end{abstract}

A Marvel Moreno le interesa menos la exploración de la subjetividad del personaje -incluso analizar su inconsciente- que la relación compleja entre el yo y los demás:

Se podría afirmar que cada personaje comienza a tener una identidad sólo en la confrontación dialéctica, en el choque, en el corto circuito, en la relación de seducción amorosa y agonizante con otro personaje. (Antonaros 206)

Hay una tensión entre la voluntad obsesiva del autor de estudiar todo y la percepción de Lina que está compuesta por versiones parciales, como si Marvel Moreno no perdiese nunca de vista el hecho de que una objetividad completa es inalcanzable en la novela, como lo es en la vida misma. Entonces es el lector quien debe formarse su propia opinión, o emoción. Observando de forma más detallada, vemos a Dora como la única opción posible para mejorar la situación económica de la familia del Valle, la misma que pertenece a la nobleza pobre, que nunca trabajó y se mantiene únicamente por alianzas matrimoniales. Es por este motivo que su madre busca defender su virginidad para salir de la miseria en la cual se encuentran. Pero Dora afirma su sexualidad manteniendo una relación con Andrés Larosca, hombre casado que llena apenas sus instintos, sin preocuparse del daño que ha ocasionado en la vida de la joven mujer. Cuando ésto es de conocimiento público, Dora pierde su dignidad, se convierte en proscrita de su círculo social; la falta de apoyo de su familia, el rechazo general y la presión social la llevan a asumir su culpa. El precio de "algo tan feo"16 es casarse con Benito Suárez, hombre violento, absolutamente despojado de compasión e incluso de sentimientos. Dora prueba satisfacer su deseo sexual cuando tiene relaciones con su marido y él se lo permite, pero cuando ella se vuelve madre, Benito le quita ese placer, actuando bajo los derechos que le atribuyen las leyes de los hombres, el patriarcado y la religión:

\footnotetext{
${ }^{16}$ Hay una situación similar en un cuento anterior a la novela, “Algo tan feo en la vida de una señora bien”: Laura se enamora y se entrega, antes de casarse, a un hombre que en vez de huir con ella, la denuncia a su madre. Se ve obligada a unirse al hombre que "acepta" una esposa que nadie quiere. Como precio por ese favor, la anula totalmente como persona.
} 
Las dificultades comenzaron cuando les nació el niño [...] pues a partir de ese momento, y con la arbitraria tenacidad que caracterizaba sus decisiones, Benito Suárez se negó a permitirle el placer a Dora alegando que su manera de provocárselo -utilizando su miembro para excitar su clítoris- era fundamentalmente perversa, aparte de que la madre de su hijo no debía regodearse en el lecho conyugal como cualquier ramera. (57)

Así, Dora se ve en la incapacidad de expresar y regular su sexualidad; más adelante, Benito la golpea, amenaza y prohibe todo, hasta afectarle en su salud: jaquecas de por vida, pólipos en los genitales, una sífilis que le produce esterilidad, una operación nasal mal hecha dado que ronca, desarreglos menstruales, hemorragias y un sinnúmero de enfermedades que la obligan a recurrir a medicinas y tranquilizantes. Ella acepta todo maltrato físico y psicológico pues está convencida que no hay ninguna otra solución y su única resistencia es la inercia infinita y silenciosa.

Catalina en cambio, entiende la importancia a la vez beneficiosa y peligrosa de la palabra y utiliza el mutismo para salvarse. Es la única que logra escapar de su marido Álvaro Espinosa -un siquiatra que utiliza su conocimiento de la naturaleza humana para manipular a los demás-. Lleva a cabo su rebelión entendiendo que la mediación es inútil. Su madre Divina Arriega, la ha educado libremente, le ha transmitido los recursos morales para asumir su destino: observar a su esposo hasta encontrar los medios para defenderse de él, empujarle al suicidio y coincidir con su propio deseo para terminar huyendo con un indio:

A sus primeros sentimientos de asombro e indignación por la suerte que como mujer le estaba destinada, se había sucedido un tranquilo egoísmo no desprovisto de desprecio hacia quienes se adaptaban o preferían resignarse, considerando fríamente que cualquier empresa de transformación social estaba fuera de su alcance y ya bastante trabajo tendría poniéndose a salvo a sí misma. Porque tal sería durante años su verdadero objetivo: encontrar la manera de escapar al poder de Álvaro Espinoza demoliendo para ello sin piedad la imagen que de su propia persona él se había construido. (149)

En definitiva, actúa como un hombre: busca el punto débil del otro, lo debilita, aniquila y hace de su propia existencia lo que desea, pero, como se trata de una mujer, la sociedad no le permite semejante libertad desafiante, ni tampoco hay hombre capaz de asumir tanta individualidad, es por esto que Catalina debe quedar fuera del grupo social al cual pertenece por nacimiento. El hecho de que la sección dedicada a Catalina esté ubicada entre las correspondientes a Dora y a Beatriz, permite mostrar por contraste la idealización del personaje.

Finalmente Beatriz es quien más ha integrado los principios morales hasta hacerlos tan suyos como para perseguir a sus familiares, empleadas e inclusive vecinos. Todo su desarreglo psíquico, emocional y sexual la lleva a adoptar una conducta masoquista que coincide a la perfección con las tendencias sádicas de Javier Freisen, con quien tiene un encuentro sexual antes del matrimonio, el mismo que ilustra la naturaleza de su relación: Javier la latiguea, gozando los dos con este acto marcado por la violencia, la humillación y el placer. Llegar al gozo mediante la fuerza permite a Beatriz liberarse de la responsabilidad de una entrega voluntaria, que sería un pecado. El tiempo se encarga de quitar el erotismo 
a la relación, haciendo de Beatriz una de esas muñecas que maltrataba cuando era niña. Los signos de su locura se acentúan, legitimando así la conducta de Javier. Ella es la última en tomar conciencia de que su entorno la considera insensata. Al hacerlo, decide morir, dejando la explosión en la cual se suicida, un espacio en blanco para la interpretación del lector. Esta tiene una virtud de catarsis, como si se disfrutara de la desaparición de todo para que cambie algo:

Alcanzaron a verla antes de que aquella horrenda deflagración estremeciera el automóvil, les abofeteara la cara, les rasgara los tímpanos y les hiriera las retinas con una inmensa ampolla de fuego que arrancó de cuajo, desde adentro, puertas y ventanas y lanzó por los aires el tejado en pedazos, de una manera pavorosa e irreal como algo no visto, sino soñado. Y luego las llamas se alzaron al cielo en una súplica muda y desesperada. (27677)

Con la lectura de estas tres existencias marcadas por el dolor y la ascensión tan difícil a su propia integridad, surge una pregunta: para poder vivir como mujer sujeto de su cuerpo y de su vida, ¿es la huida la única opción ? Es decir, ¿si Marvel Moreno, que fue Reina del Carnaval -como Catalina-, que tuvo una madre neurótica e inquisidora -como Dora-, que perteneció a la clase dominante-como Beatriz-, no se hubiera alejado de esa sociedad clasista, sexista y racista, habría acaso terminado destrozada, mutilada aniquilada? Más allá del cuestionamiento, lo que se plantea es el pesimismo absoluto y sin remedio del retrato que hace la escritora de este mundo costeño que ella rechazó y que se encuentra omnipresente en su obra literaria. ¿Cuál es el destino posible para una Barranquillera ?, ¿suicidarse como Beatriz?, ¿prostituirse como Maria Fernanda?, ¿drogarse como Dora?, ¿asesinar como Doña Genoveva? Ciertamente resistir parece imposible, por lo menos de manera durable y/o eficiente:

Su significativo aporte es la recuperación de un mundo femenino semitransgresor, que trasmite oral y gestualmente las tretas del débil y enseña, así, a sobrevivir en vidas dobles, matando, poseyendo, anestesiándose y obteniendo placeres tan parciales y dudosos que solo denuncian su real ineficacia. (Ordoñez 197)

Así que para no ser una sobreviviente o una moribunda, la única salida parece ser la de vivir lejos como Marvel, Lina, y Cata-lina. Si bien es cierto que Marvel Moreno se dedica a verbalizar la necesidad que tiene la mujer de encontrar su propia sexualidad, de vivirla y aceptarla, frente a las voces del poder -la madre y lo masculino-, tampoco hace de los personajes masculinos agentes concientes de su papel, o sea los hombres también padecen ese sistema que perpetúan: el machismo, esa "patología de la virilidad” como lo define Elizabeth Burgos, mutila la sexualidad masculina. En la novela, Benito Suárez y Álvaro Espinosa se suicidan y Javier queda viudo y sin hijos, por no haber sido capaces de aceptar la sexualidad femenina como expresión del otro yo. ${ }^{17}$

\footnotetext{
${ }^{17}$ Solo el negro Lorenzo (amante de Lucila) y el indio (amante de Catalina) escapan a ese modelo por estar alejados de los valores morales del catolicismo y fuera de la cultura patriarcal: el indio se encuentra fuera porque pertenece a otro tipo de sociedad y el Negro porque vive de otra manera.
} 
Hombres como mujeres son víctimas a la vez del sistema y de ellos mismos, es por eso que no hay ni héroe ni triunfadores. Si Marvel Moreno cuestiona el lugar ocupado por las mujeres en la sociedad, es también para deplorar el hecho de que los hombres no pueden asumirse generosamente ante ellas. Al mejorar la condición femenina mejoraría la condición humana, al considerar el feminismo como un humanismo. Por lo demás, cuando preguntaban a Marvel Moreno a quién dirigía su obra, contestaba: “a un lector indefinido mayor de 30 años” (Damjanova, "La voz femenina” 109), por estar convencida que la sexualidad es aquello que permite medir el yo de los personajes, observando su singularidad a través de esa experiencia individual.

Por medio de lo imaginario, Marvel Moreno traduce esa gran obsesión colectiva que oprime a la mujer por su condición genérica, describiendo un mundo sin amor donde se confunden poder y sexo, donde mujeres aplastadas y asustadas, que soportan frustraciones y arbitrariedades con los ojos abiertos, tienen sed de cariño y de emancipación pues saben que luchar contra el poder es la única forma de afirmar el yo.

Este es el mensaje que nos dejó Marvel con su interpretación del mundo:

El despertar del deseo en la mujer y el difícil acceso a su realización mediante el encuentro con el cuerpo del hombre, es uno de los temas recurrentes en la narrativa de Marvel Moreno, y tal vez el resorte principal de su obra. (Burgos 99)

En la novela, En diciembre llegaban las brisas, la autora cuenta, describe, desmenuza, penetra, problematiza, nos atrapa con su sentido de la precisión europea y esa profusión caribeña, transformándonos en mirones, observando al personaje y su entorno. Para ilustrar la relación entre sexualidad y poder en una sociedad opresora, la autora utiliza una técnica que es de su total dominio: contar un hecho y presentar el análisis del mismo para demostrar los efectos perversos de la educación tradicional y de los valores morales católicos sobre el comportamiento femenino en general, logra así alejarse de lo local para llegar a lo universal.

Soy solidaria con las mujeres, como lo soy con los negros, los judíos o los árabes cuando son perseguidos o humillados por su condición de seres que presentan características diferentes a las de quienes detentan el poder. ${ }^{18}$

En diciembre llegaban las brisas es una "Biblia” sobre el deseo y los instintos, más una constatación que un proyecto, porque Marvel no propone un modelo de sociedad alternativa a ese mundo cerrado y rígido. La multitud de personajes, la densidad temática, la complejidad formal, la precisión analítica casi obsesiva y la autonomía así como la mezcla de diferentes escuelas de pensamiento, son tantos elementos que demuestran el lugar esencial de Marvel Moreno en la literatura.

Es por este motivo que, más allá de la lectura crítica del “cuerpo” de la estructura del texto, se trata también de difundir la obra de una escritora marginalizada por asuntos extra-

${ }^{18}$ Ver también "denunciar la opresión que se ejerce sobre una niña es denunciar la opresión en general aún si la niña nació burguesa y murió en las aguas del Caribe” (La obra de Marvel Moreno... $\mathrm{V})$. 
literarios, pero que debería ocupar un espacio legítimo en la producción femenina contemporánea, su producción corresponde a la definición de Ariel Castillo Mier:

\footnotetext{
Literatura que se cuestiona a sí misma, que no ignora lo absurdo, lo mágico, lo oscuro; literatura que incorpora una crítica de la vida, un proyecto existencial pleno de vitalismo que reivindica el deseo, el goce de los sentidos y de la imaginación, que lanza un grito de desobediencia frente a lo establecido; que propone dudas, que mezcla géneros, que registra el habla popular sin deformarla, que se apropia de la música popular y de los códigos del cine; literatura de masas y de la risa sana del canarval; literatura que busca, que se opone a la disolución definitiva, en total independencia frente a la golosina de poder; literatura que construye un espacio para la comprensión y la discusión de las ideas, las conductas, la historia y la sociedad. (Castillo Mier 50)
}

Al final del texto, el lector espera el arribo de diciembre, que lleguen las brisas para refrescar ese mundo asfixiante, aunque sabemos todos que las brisas no cambian muchas cosas, solamente "lo que el viento se llevó". Ahora, el imperfecto del título nos recuerda que ya pasó, que ya no está y que si las brisas llegan en diciembre de todas maneras se van en febrero con el Carnaval.

\section{BiBLIOGRAFÍA}

Antonaros, Alfredo. "Rutas, senderos, itinerarios en la novela". La obra de Marvel Moreno. Actas del Coloquio Internacional, Toulouse, 3-5 de abril de 1997. Viareggio, Mauro Baroni, editor, 1997. 203-12.

Araújo, Helena. La Sherezada Criolla. Bogotá: Universidad Nacional de Colombia, 1989.

Badinter, Elizabeth. L'Un est l'Autre. Paris: Odile Jacob, 1986.

Bourneuf, Roland. Ouellet Réal. L'univers du roman. Paris: Puf, 1995

Burgos, Elizabeth. "Feminidad, feminismo y escritura. Negación del deseo, poder de la madre y escritura en la narrativa de Marvel Moreno”. La obra de Marvel Moreno. Actas del Coloquio Internacional, Toulouse, 3-5 de abril de 1997. Viareggio, Mauro Baroni, editor, 1997. 99-106.

Castillo Mier, Ariel. “Dos veces el mar: de Amira a Marvel”. La obra de Marvel Moreno. Actas del Coloquio Internacional, Toulouse, 3-5 de abril de 1997. Viareggio, Mauro Baroni, editor, 1997. 43-50.

Ciplijauskaite, Biruté. La novela femenina contemporánea. Barcelona: Anthropos, 1988. Damjanova, Ludmila. Sexo y lenguaje. Buenos Aires: UMA, 1996.

"La voz femenina de Marvel Moreno: la empatía como medio de acceso a sus protagonistas” en La obra de Marvel Moreno. Actas del Coloquio Internacional, Toulouse, 3-5 de abril de 1997. Viareggio, Mauro Baroni, editor, 1997. 107-15.

Fourrier, Jacques. “La personalidad de Marvel Moreno”. La obra de Marvel Moreno. Actas del Coloquio Internacional, Toulouse, 3-5 de abril de 1997. Viareggio, Mauro Baroni, editor, 1997. 21-29. 
Gilard, Jacques. “La obra de Marvel Moreno: elementos para una cronología”. La obra de Marvel Moreno. Actas del Coloquio Internacional, Toulouse, 3-5 de abril de 1997. 181-99.

Guerra-Cunningham. "Pluralidad cultural y voces de la otredad en la novela latinoamericana”. Asedios a la heterogeneidad cultural, libro de homenaje a Antonio Cornejo Polar. Philadelphia: Asociación Internacional de Peruanistas, 1996. 25971.

Josefina, Ludmer. “Tretas del débil”. La sartén por el mango. Puerto Rico: Ediciones Huracán, 1985. 47-54.

Moreno, Marvel. Algo tan feo en la vida de una señora bien. Bogotá: Pluma, 1980. En diciembre llegaban las brisas. Barcelona: Plaza y Janés, 1987. El encuentro y otros cuentos. Bogotá: El Ancora, 1992.

Olaciregui,Julio. “Marvel Luz, Marvel sombra”, “Marvel Luz, Marvel sombra”. La obra de Marvel Moreno, Actas del Coloquio Internacional, Toulouse, 3-5 de abril de 1997. 93-96.

Ordoñez, Montserrat. “Marvel Moreno: Mujeres de ilusiones y elusiones”. De ficciones y relaidades, Perspectivas sobre literatura e historia colombianas. Memorias del Quinto Congreso de Colombianistas, Cartagena, Tercer Mundo Editores, 1989. 19398.

Perilli, Carmen. "Mujer e identidad en la narrativa latinoamericana de fines del milenio”. Memorias de Jalla. Vol. II. (Tucumán, 1995): 476-87. 